University of Nebraska - Lincoln

DigitalCommons@University of Nebraska - Lincoln

Biological Systems Engineering: Papers and

Publications

Biological Systems Engineering

2005

\title{
Policosanol Contents and Compositions in Wax-Like Materials Extracted from Selected Cereals of Korean Origin
}

\author{
Keum Taek Hwang \\ Chonbuk National University \\ Ji Eun Kim \\ Chonbuk National University \\ Curtis L. Weller \\ University of Nebraska-Lincoln, cweller1@unl.edu
}

Follow this and additional works at: https://digitalcommons.unl.edu/biosysengfacpub

Part of the Biological Engineering Commons

Hwang, Keum Taek; Kim, Ji Eun; and Weller, Curtis L., "Policosanol Contents and Compositions in WaxLike Materials Extracted from Selected Cereals of Korean Origin" (2005). Biological Systems Engineering: Papers and Publications. 109.

https://digitalcommons.unl.edu/biosysengfacpub/109

This Article is brought to you for free and open access by the Biological Systems Engineering at DigitalCommons@University of Nebraska - Lincoln. It has been accepted for inclusion in Biological Systems Engineering: Papers and Publications by an authorized administrator of DigitalCommons@University of Nebraska Lincoln. 


\title{
Policosanol Contents and Compositions in Wax-Like Materials Extracted from Selected Cereals of Korean Origin
}

\author{
Keum Taek Hwang, ${ }^{1.2}$ Ji Eun Kim, ${ }^{1}$ and Curtis L. Weller ${ }^{3}$
}

Policosanols, long-chained alcohols, have been reported to have beneficial physiological activities. Content and composition of policosanols in wax-like materials extracted from selected cereals of Korean origin were determined. Wax-like materials were extracted using hot hexane. Yields of wax-like materials from unpolished grain sorghum, polished grain sorghum, brown rice, purple rice, wheat, and maize were 223, 37, 33, 61,
10 , and $10 \mathrm{mg} / 100 \mathrm{~g}$ of dry kernels, respectively. Policosanol contents, as determined using HPLC, in the wax-like materials from the cereals were $33,29,6,0$, and $2 \%(\mathrm{w} / \mathrm{w}, \mathrm{db})$, respectively. Major alcohols in the policosanols from grain sorghum were octacosanol and triacontanol. Docosanol was the major alcohol in the policosanols from brown rice, purple rice, wheat, and maize.
Policosanols are a mixture of primary long-chained alcohols and are available commercially as nutritional supplements containing mostly octacosanol (28:0), triacontanol (30:0), hexacosanol (26:0), and dotriacontanol (32:0). They have been produced from sugar cane, beeswax, and kernels of cereal grains. Policosanols have beneficial physiological activities such as improving blood lipid levels (Aruzazabala et al 1994; Kato et al 1995; Gouni-Berthold and Berthold 2002), reducing platelet aggregation (Aruzazabala et al 1996), improving exercise performance of coronary heart disease patients (Stüsser et al 1998), and increasing muscle endurance (Kabir and Kimura 1995). However, Wang et al (2003) reported that policosanols have no significantly favorable effect in changing blood lipid levels of hamsters. Recently, nutritional significance and metabolism of policosanols were reviewed by Hargrove et al (2004).

Surfaces of kernels of cereal grains are covered with epicuticular wax, which appears to regulate the water balance of the parent plant by reducing evaporation to minimize mechanical damage to cells and to inhibit fungal and insect attacks. Bianchi et al (1979) and Avato et al (1990) extracted wax-like materials (WLM) from grain sorghum grown in Italy and reported that the WLM consisted of alcohols ( 32 and $34 \%$, w/w, db, respectively), otherwise known as policosanols, acids ( 24 and $27 \%$, respectively), and aldehydes (21 and 32\%, respectively), fractionated by column chromatography. Recently, Hwang et al (2002a,b; 2004) confirmed that aldehydes, alcohols (policosanols), and acids were the major components of the WLM extracted from grain sorghum grown in the United States in Nebraska, comprising 46-55\% (w/w, db), 37-41\%, and 4-7\%, respectively, as determined by HPLC.

Other cereal grains have not been studied extensively regarding their policosanol contents. Bianchi et al (1984) extracted wax from maize kernels using chloroform, reporting a wax mass of $2.7 \mathrm{mg}$ recovered from 20 hand-harvested and hand-shelled ears. They reported esters comprised $76 \%(\mathrm{w} / \mathrm{w}, \mathrm{db})$ of the wax and alcohols comprised $2 \%$. According to the study by Kawanishi et al (1991), octacosanol contents in germs of rice, wheat, and maize were $0.46,0.22$, and $0.82 \mathrm{mg} / 100 \mathrm{~g}$, respectively. They reported petroleum ether-extractable materials (including waxes and oils) in the germs, but did not report levels of WLM.

\footnotetext{
${ }^{1}$ Department of Food Science and Human Nutrition, and Center for Healthcare Technology Development, Chonbuk National University, Jeonju, Jeonbuk, 561 756. Korea.

${ }^{2}$ Corresponding author. Phone: +82-63-270-3857. Fax: +82-63-270-3854. E-mail keum@chonbuk.ac.kr

${ }^{3}$ Department of Biological Systems Engineering, University of Nebraska, Lincoln, NE 68583
}

The objectives of this study were to determine and compare yield and composition of WLM (recovered using hot hexane and precipitated in a cold environment) extracted from grain sorghum, brown rice, purple rice, wheat, and maize, all of Korean origin, and to determine the content and composition of policosanols in the WLM.

\section{MATERIALS AND METHODS}

\section{Raw Materials}

Intact kernels of unpolished grain sorghum (purple), abrasively polished grain sorghum (purple color partially retained), brown rice (round japonica type), purple rice (unpolished long grain), wheat (soft, winter, red), and maize (flint, yellow) were obtained from a local market in Jeonju, Korea. The cereal kernels used in the study were grown in Korea. The parent grain sorghum plants were tall and their heads drooped upon ripening. The color of the pericarp of the grain sorghum kernels was purplish, whereas the endosperm was creamy white. An abrasive type of polishing machine (IDP-3000, Ideal System Co., Daegu, Korea) was used for polishing of grain sorghum. Yield of polished sorghum from whole grains was $70-75 \%$. Polished sorghum kernels retained a portion of the purple pericarp on their surfaces. The polished sorghum kernels are a common food material in Korea.

\section{Extraction of Wax-Like Materials from Cereals}

Extraction of WLM from whole cereal kernels followed the same method as in Hwang et al (2004). Cereal kernels were washed with tap water and dried at $45^{\circ} \mathrm{C}$ over $24 \mathrm{hr}$. Kernels ( $800 \mathrm{~g}$ at $\approx 10 \%$ [wb] moisture) with $800 \mathrm{~mL}$ of hexane were refluxed for $30 \mathrm{~min}$. The mixture was filtered through a coffee filter paper lying on top of a Whatman No. 2 filter paper (Whatman, Maidstone, Kent, UK). The filtrate was placed in a freezer at $-18^{\circ} \mathrm{C}$ for at least $8 \mathrm{hr}$. Filtering the cold miscella on to Whatman No. 42 filter paper, which was then desolvented under vacuum, collected the precipitate of the WLM.

\section{TLC of Wax-Like Materials Extracted from Cereals}

Thin-layer chromatography (TLC) separation of WLM extracted from cereals was completed as in the previous report (Hwang et al $2002 \mathrm{a})$. The WLM dissolved in hexane $(\approx 100 \mu \mathrm{g} / 10 \mu \mathrm{L})$ were spotted on a TLC plate (general purpose, $20 \times 20 \mathrm{~cm}$, particle size $250 \mu \mathrm{m}$ ) (Aldrich Chemical Co., Milwaukee, WI). The developing solvent was hexane, diethyl ether, and acetic acid (85:15:2, v/v). Developed bands were visualized by dipping the plate in a solution of $10 \mathrm{~g}$ of cupric sulfate dissolved in $100 \mathrm{~mL}$ of $8 \%$ phosphoric acid for $5 \mathrm{sec}$, letting it dry for $5 \mathrm{~min}$, and heating it in an oven at $\approx 150^{\circ} \mathrm{C}$ until the developed bands were charred. 


\section{Compositional Analysis of Wax-Like Materials Using HPLC}

Policosanol content along with contents of major components in the WLM extracted from cereal kernels were determined using an HPLC system as in Hwang et al (2002b; 2004). Two HPLC pumps (510, Waters Corp., Milford, MA) were operated in gradient modes. Flow rate of mobile phase was $1 \mathrm{~mL} / \mathrm{min}$. Column was a Luna $5 \mu$ silica column $(250 \mathrm{~mm}$ length $\times 4.6 \mathrm{~mm}$ i.d.) (Phenomenex, Torrance, CA). The column was heated at $40^{\circ} \mathrm{C}$ using a Waters column heater module. Exposed lines between injection loop and detector connection were maintained at $\approx 38-40^{\circ} \mathrm{C}$ by wrapping in heating tape. Detector was a Varex ELSD II (Rockville, MD) operated at $50^{\circ} \mathrm{C}$ with nitrogen pressure of $930 \mathrm{kPa}$. Samples were dissolved in hexane at $20 \mu \mathrm{g} / 100 \mu \mathrm{L}$, and $100 \mu \mathrm{L}$ of each was injected.

\section{Compositional Analysis of Policosanols Fractionated from Wax-Like Materials of Cereals Using GC}

Policosanol composition in WLM from whole cereals followed the same method as Hwang et al (2004). Policosanol fraction (2 $\mathrm{mL}$ ) was collected from $20 \mu \mathrm{g}$ of WLM using HPLC. Policosanol composition was determined using GC. To desolventized policosanol fraction, $0.2 \mathrm{~mL}$ of chloroform and $0.05 \mathrm{~mL}$ of $\mathrm{N}$-methyl-N(trimethylsilyl)trifluoroacetamide (Sigma Chemical, St. Louis, MO) were added. The content was heated at $60^{\circ} \mathrm{C}$ for $10 \mathrm{~min}$ to make trimethylsilyl (TMS) ether derivatives. A standard mixture of palmityl alcohol, stearyl alcohol, eicosanol, behenyl alcohol, tricosanol, lignoceryl alcohol (Nu-Chek Prep, Inc., Elysian, MN), hexacosanol, heptacosanol, octacosanol, and triacontanol (Sigma Chemical) containing 1-8 $\mathrm{gg}$ of each in $0.2 \mathrm{~mL}$ of chloroform was prepared and derivatized in the same manner as above for identifying the retention times of the alcohols and for calculating their response factors. The TMS ether derivative solution $(2 \mu \mathrm{L})$ was injected into a gas chromatography system (GC) (HP6890, Hewlett-Packard Co., Wilmington, DE) equipped with a DB-5 column (30 m, $0.25 \mathrm{~mm}$ i.d., and $0.25 \mu \mathrm{m}$ film thickness) (J\&W Scientific, Folsom, CA) and using a carrier gas of helium. Detector was a flame-ionization detector. Injector and detector temperatures were both set at $315^{\circ} \mathrm{C}$. Oven was programmed to start and hold at $150^{\circ} \mathrm{C}$ for $1 \mathrm{~min}$ before increasing to $210^{\circ} \mathrm{C}$ at $20^{\circ} \mathrm{C} / \mathrm{min}$, increasing to $310^{\circ} \mathrm{C}$ at $4^{\circ} \mathrm{C} / \mathrm{min}$, holding at $310^{\circ} \mathrm{C}$ for $1 \mathrm{~min}$, increasing to $315^{\circ} \mathrm{C}$ at $25^{\circ} \mathrm{C} / \mathrm{min}$, and finally holding for $5 \mathrm{~min}$.

Content, yield, and composition values are means of three determinations except for composition of the WLM and policosanol composition of maize.

\section{RESULTS AND DISCUSSION}

Moisture and crude lipid contents of cereal grains observed in the study are shown in Table I. Crude lipids in unpolished and polished grain sorghum were 4.8 and $2.6 \%$ (w/w, wb), respectively, indicating lipids still remain after the polishing of grain sorghum kernels. Purple rice was a little higher in lipid content than brown rice. Whole wheat contained $<1 \%$ lipids.
Yield of WLM extracted from grain sorghum was $223 \mathrm{mg} / 100$ $\mathrm{g}$ of dry kernels (Table I), similar to the values from various grain sorghum types produced in Nebraska $(200-300 \mathrm{mg} / 100 \mathrm{~g}$ of dry kernels (Hwang et al 2004). A fairly large amount of WLM (37 $\mathrm{mg} / 100 \mathrm{~g}$ of dry kernels) still remained on the polished grain sorghum. WLM levels from brown rice, purple rice, wheat, and maize were fairly low compared with those of grain sorghum.

TLC of WLM extracted from whole grain sorghum resulted in two dark spots representing aldehydes and policosanols and some light spots representing hydrocarbons, wax esters and steryl esters (WE/SE), and acids (Fig. 1). Quantitative composition of the WLM of whole grain sorghum, analyzed by HPLC, was $57 \%$ (w/w) aldehydes, $33 \%$ policosanols, $4 \%$ acids, $2 \%$ hydrocarbons, and 1\% triacylglycerols (Fig. 2, Table I). WE/SE did not appear on the HPLC results. TLC of WLM from polished grain sorghum showed darker spots for WE/SE, triacylglycerols, and acids compared with TLC of unpolished grain sorghum (Fig. 1). It is consistent with the HPLC results (Fig. 2, Table I). Aldehydes $(34 \%)$ and policosanols $(29 \%)$ were still major components of the WLM extracted from polished grain sorghum.

While WE/SE were not detected in the WLM from whole grain sorghum, a fairly large quantity of WE/SE (13\%) was detected in the WLM from the polished grain sorghum. It implies that WE/SE may exist in the inner parts of grain sorghum kernels rather than on the surfaces.

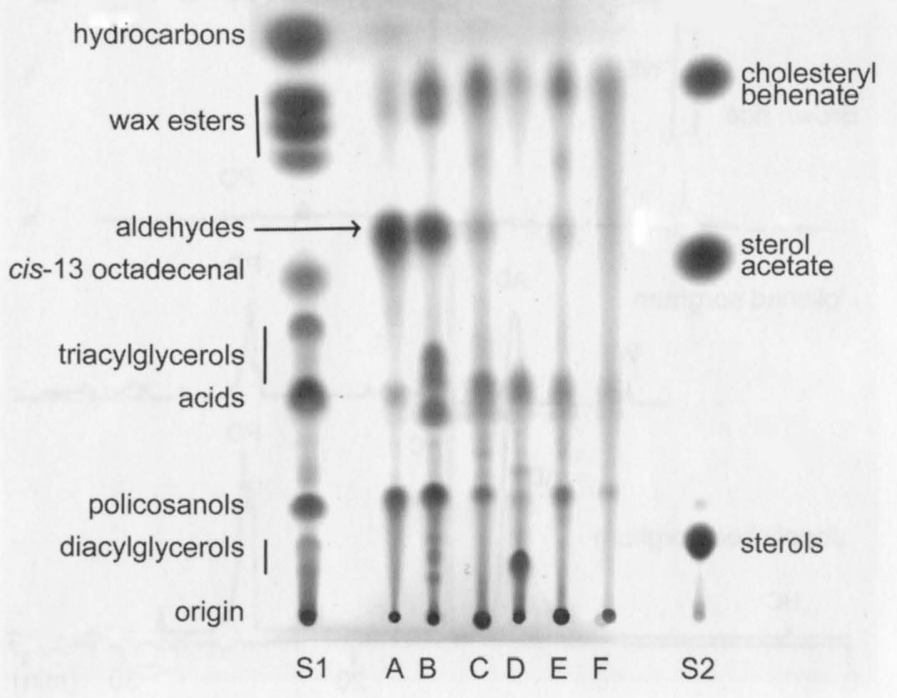

Fig. 1. Thin-layer chromatography of wax-like materials extracted from selected cereal grains of Korean origin using developing solvent of hexane, diethyl ether, and acetic acid $(85: 15: 2)$. S1 and S2, standard mixtures; A, unpolished grain sorghum; B, polished grain sorghum; C, brown rice; $\mathrm{D}$, whole wheat; $\mathrm{E}$, purple rice; $\mathrm{F}$, maize.

TABLE I

Composition of Wax-Like Materials (WLM) Hexane-Extracted from Selected Cereal Grains of Korean Origin ${ }^{\mathrm{a}}$

\begin{tabular}{|c|c|c|c|c|c|c|c|c|c|c|}
\hline \multirow[b]{2}{*}{ Cereal Grain $^{\text {b }}$} & \multirow{2}{*}{$\begin{array}{l}\text { Moisture } \\
(\%, w / w)\end{array}$} & \multirow{2}{*}{$\begin{array}{l}\text { Crude Lipids } \\
(\%, w / w, w b)\end{array}$} & \multirow{2}{*}{$\begin{array}{c}\text { WLM Yield } \\
(\mathrm{mg} / 100 \mathrm{~g}, \mathrm{db})\end{array}$} & \multicolumn{7}{|c|}{ HPLC-Analyzed Composition of $\mathrm{WLM}^{\mathrm{c}}(\%, w / w)$} \\
\hline & & & & PO & AD & AC & $\mathrm{HC}$ & TG & WE/SE & UK \\
\hline Grain sorghum UP & $8.9(0.06)$ & $4.8(0.33)$ & $223(48)$ & $33.4(2.3)$ & $56.8(3.2)$ & $4.3(0.5)$ & $2.3(0.3)$ & $1.2(0.2)$ & $n d^{d}$ & \\
\hline Grain sorghum P & $6.0(0.04)$ & $2.6(0.05)$ & $36.6(5.3)$ & $29.2(1.8)$ & $34.0(6.4)$ & $13.1(1.8)$ & $4.4(0.8)$ & $5.3(1.7)$ & $13.3(3.4)$ & \\
\hline Brown rice & $7.2(0.10)$ & $1.6(0.12)$ & $32.9(7.8)$ & $5.7(1.6)$ & nd & $12.1(0.4)$ & nd & $1.8(0.1)$ & $79.2(1.0)$ & \\
\hline Purple rice UP & $8.0(0.09)$ & $2.0(0.03)$ & $61.2(2.7)$ & $6.0(1.9)$ & nd & $9.6(2.0)$ & $2.0(0.5)$ & nd & $81.0(7.8)$ & \\
\hline Whole wheat & $7.1(0.25)$ & $0.7(0.11)$ & $9.6(2.4)$ & nd & nd & $8.4(0.8)$ & $5.8(2.1)$ & nd & $7.5(1.3)$ & $79.2(7.3)$ \\
\hline Maize & $12.1(0.03)$ & $2.0(0.25)$ & $9.7(1.4)$ & 2.1 & nd & 2.5 & nd & nd & 93.5 & \\
\hline
\end{tabular}

${ }^{a}$ Mean values with standard deviation (in parentheses) of three determinations (except for maize for WLM composition from a single determination).

${ }^{\mathrm{b}} \mathrm{UP}$, unpolished; P, polished.

c PO, policosanols: AD, aldehydes; AC, acids; HC, hydrocarbons; TG, triacylglycerols; WE/SE, wax esters and steryl esters; UK. unknown.

${ }^{\mathrm{d}}$ Not detected. 
Triacylglycerols, which are mainly present in the inner part of grain sorghum, were more prevalent in the WLM recovered from polished grain sorghum $(5 \%)$ than unpolished grain sorghum (1\%) (Table I). Detection of higher levels of acids in WLM recovered from polished grain sorghum (13\%) than from unpolished grain sorghum might result from inclusion of fatty acids, enzymatic hydrolysis products of regular lipids by tissue damage during polishing.

WE/SE were the major component of WLM extracted from brown rice $(79 \%)$, purple rice $(81 \%)$, and maize (94\%) (Figs. 1 and 2; Table I). Presence of steryl esters in the WLM was not observed because pink coloration did not appear on TLC plates during charring (steryl esters turn pink during charring on the TLC system used in the study). WLM extracted from brown rice, purple rice, and maize consisted of $<10 \%$ policosanols (Table I).

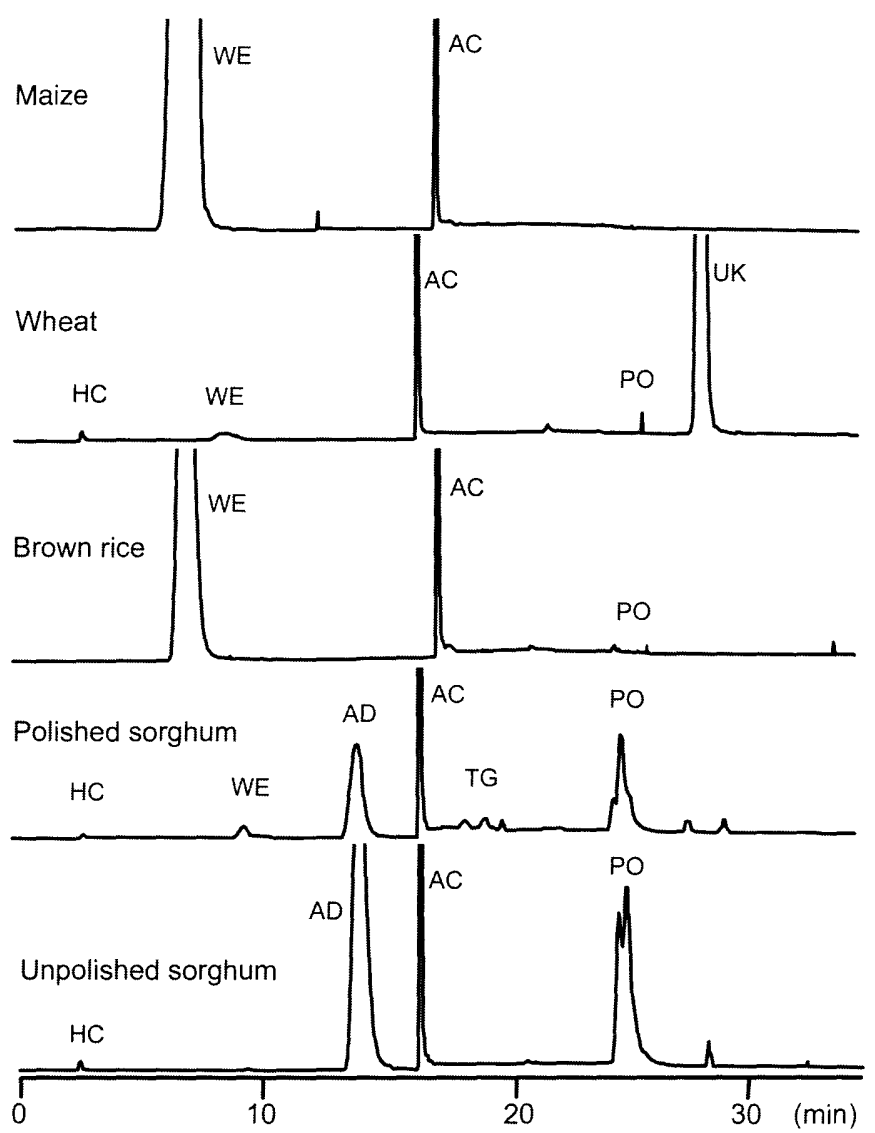

Fig. 2. HPLC of wax-like materials extracted from selected cereal grains of Korean origin. HC, hydrocarbons; WE, wax esters and steryl esters; AD, aldehydes; AC, acids; TG, triacylglycerols; PO, policosanols; UK, unknown.
Policosanols were not detected in HPLC of the WLM from wheat, although a light band corresponding to policosanols appeared on TLC plates (Fig. 1). Aldehydes were not detected in the cereal grains other than grain sorghum (Table I). A large amount of fairly polar materials was detected as shown in Figs. 1 and 2 for TLC and HPLC of the WLM from whole wheat. These materials were not identified in this study.

Policosanols were fractionated from WLM using HPLC, followed by trimethylsilyl ether derivatization for GC analysis. GC results of policosanol compositions for the cereals are shown in Table II. Octacosanol was the most abundant policosanol (46\%) in the grain sorghum tested in the study, followed by triacontanol $(30 \%)$. Policosanols in grain sorghum grown in Nebraska were composed of $44 \%$ octacosanol and $41 \%$ triacotanol (Hwang et al 2004). The polishing process changed the policosanol composition of grain sorghum very little (Table II). In brown rice and purple rice, docosanol was the most abundant ( 34 and $35 \%$, respectively), followed by triacontanol (27 and $29 \%$, respectively), and octacosanol (13 and 11\%, respectively). The policosanol peak for WLM of wheat was not observed in HPLC (Fig. 2). However, policosanols were present enough in the WLM of wheat to be analyzed by GC. Policosanols in wheat consisted of $42 \%$ docosanol, 17\% hexacosanol, and 16\% octacosanol (Table II). Docosanol was the most abundant policosanol $(50 \%)$ in maize also.

In conclusion, high yield of WLM from grain sorghum and high content of policosanols in the WLM compared with other cereal grains imply that grain sorghum is an exceptional source of policosanols. Existence of policosanols as free forms in sorghum is another advantage as well as their abundance. Free alcohols and acids hydrolyzed from wax esters are readily absorbed in the intestine. However, digestion of wax esters in mammals is limited (Place 1992). Production of policosanols from wax esters in sources other than grain sorghum requires a saponification process. Recovery and preparation of grain sorghum policosanols does not require a saponification step. Higher content of octacosanol and triacontanol in grain sorghum also would be an incomparable advantage against other cereal grains when judging commercial policosanol products on the basis of higher octacosanol and triacontanol levels.

\section{ACKNOWLEDGMENTS}

A contribution of Chonbuk National University, Korea, and the University of Nebraska Agricultural Research Division, Lincoln, NE, Journal Series No.14693. This research was supported in part by funds provided by Chonbuk National University, Korea and through the Hatch Act.

\section{LITERATURE CITED}

Arruzazabala, M. L., Carbajal, D., Mas, R., Molina, V., Valdes, S., and Laguna, A. 1994. Cholesterol-lowering effects of policosanol in rabbits. Biol. Res. 27:205-208.

Arruzazabala, M. L., Valdes, S., Mas, R., Fernandez, L., and Carbajal, D.

TABLE II

Gas Chromatography Results for Policosanols Separated from Wax-Like Materials in Selected Cereal Grains of Korean Origin ${ }^{a}$

\begin{tabular}{|c|c|c|c|c|c|c|c|c|c|c|}
\hline \multirow[b]{2}{*}{ Cereal Grain ${ }^{b}$} & \multirow{2}{*}{$\begin{array}{c}\text { Total Policosanols } \\
\text { (mg/100 g, } \\
\text { w/w, db) }\end{array}$} & \multicolumn{9}{|c|}{ Alcohols $(\%, w / w)$} \\
\hline & & $20: 0$ & $22: 0$ & $23: 0$ & $24: 0$ & $26: 0$ & $27: 0$ & 28:0 & 29:0 & $30: 0$ \\
\hline Grain sorghum UP & 74.5 & $1.1(0.3)$ & $6.2(0.5)$ & $1.3(0.3)$ & $3.4(0.8)$ & $9.2(2.6)$ & $1.0(0.3)$ & $45.5(4.0)$ & $2.1(0.3)$ & $30.2(4.3)$ \\
\hline Grain sorghum $\mathrm{P}$ & 9.8 & $1.1(0.1)$ & $5.4(0.7)$ & $1.3(0.4)$ & $2.7(0.2)$ & $14.6(0.2)$ & $0.8(0.0)$ & $45.6(1.2)$ & $1.0(0.1)$ & $27.3(0.2)$ \\
\hline Brown rice & 1.9 & $7.7(1.1)$ & $33.9(3.6)$ & $9.4(4.2)$ & $n d^{\mathrm{c}}$ & $7.1(0.7)$ & nd & $12.7(2.2)$ & nd & $29.3(2.7)$ \\
\hline Purple rice UP & 3.7 & $6.8(0.3)$ & $34.8(1.7)$ & $10.2(1.5)$ & $1.8(0.1)$ & $8.7(0.2)$ & nd & $10.6(0.2)$ & nd & $27.1(1.4)$ \\
\hline Whole wheat & $\operatorname{trace}^{\mathrm{d}}$ & $8.4(0.4)$ & $42.0(1.3)$ & $10.2(0.3)$ & $6.8(0.3)$ & $17.0(0.1)$ & nd & $15.7(1.1)$ & nd & nd \\
\hline Maize & 0.2 & 10.4 & 50.2 & 19.7 & nd & 7.5 & nd & 12.4 & nd & nd \\
\hline
\end{tabular}

${ }^{a}$ Mean values with standard deviation (in parentheses) of three determinations (except for maize for policosanol composition from a single determination).

${ }^{\mathrm{b}} \mathrm{UP}$, unpolished; P, polished.

c Not detected.

d Not detected by HPLC, but detected by TLC. 
1996. Effect of policosanol successive dose increases on platelet aggregation in healthy volunteers. Pharmacol. Res. 34:181-185.

Avato, P., Bianchi, G., and Murelli, C. 1990. Aliphatic and cyclic lipid components of sorghum plant organs. Phytochemistry 29:1073-1078.

Bianchi, G., Avato, P., and Mariani, G. 1979. Composition of surface wax from sorghum grain. Cereal Chem. 56:491-492.

Bianchi, G., Avato, P., and Salamini, F. 1984. Surface waxes from grain, leaves, and husks of maize (Zea mays L.). Cereal Chem. 61:45-46.

Gouni-Berthold, I., and Berthold, H. K. 2002. Policosanol: Clinical pharmacology and therapeutic significance of a new lipid-lowering agent. Am. Heart J. 143:356-365.

Hargrove, J. L., Greenspan, P., and Hartle, D. K. 2004. Nutritional significance and metabolism of very long chain fatty alcohols and acids from dietary waxes. Exp. Biol. Med. 229:215-226.

Hwang, K. T., Cuppett, S. L., Weller, C. L., Hanna, M. A., and Shoemaker, R. K. 2002a. Aldehydes in grain sorghum wax. J. Am. Oil Chem. Soc. 79:529-533.

Hwang, K. T., Cuppett, S. L., Weller, C. L., and Hanna, M. A. 2002b. HPLC of grain sorghum wax classes highlighting separation of aldehydes from wax esters and steryl esters. J. Separation Sci. 25:619-623.

Hwang, K. T., Weller, C. L., Cuppett, S. L., and Hanna, M. A. 2004. Policosanol contents and compositions of grain sorghum kernels and dried distillers grains. Cereal Chem. 81:345-349.

Kabir, Y., and Kimura, S. 1995. Tissue distribution of (8-14C)-octacosanol in liver and muscle of rats after serial administration. Ann. Nutr. Metab. 39:279-284

Kato, S., Karino, K.-I., Hasegawa, S., Nagasaki, A., Eguchi, M., Ichinose, T., Tago, K., Okumori, H., Hamatani, K., Takahashi, M., Ogasawara, J., Masushige, S., and Hasegawa, T. 1995. Octacosanol affects lipid metabolism in rats fed on a high-fat diet. Br. J. Nutr. 73:433-441.

Kawanishi, K., Aoki, K., Hashimoto, Y., and Matsunobu, A. 1991. Free primary alcohols in oils and waxes from germs, kernels and other components of nuts, seeds, fruits and cereals. J. Am. Oil Chem. Soc. 68:869-872.

Place, A. R. 1992. Comparative aspects of lipid digestion and absorption: Physiological correlates of wax ester digestion. Am. J. Physiol. 263:R464-R471.

Stüsser, R., Batista, J., Padrón, R., Sosa, F., and Pereztol, O. 1998. Longterm therapy with octacosanol improves treadmill exercise-ECG testing performance of coronary heart disease patients. Int. J. Clin. Pharmacol. Ther. 36:469-473.

Wang, Y. W., Jones, P. J. H., Pischel, I., and Fairow, C. 2003. Effects of policosanols and phytosterols on lipid levels and cholesterol biosynthesis in hamsters, Lipids 38:165-170.

[Received October 25, 2004. Accepted January 26, 2005.] 